\title{
LA FUNCION PUBLICA LOCAL DE CARA A SU REFORMA
}

35.08: 352

por

\section{Luis Martín Rebollo}

Catedrático de Derecho Administrativo en la Universidad de Extremadura

SUMARIO: I. EL PROYECTO DE LEY REGULADORA DE LAS BASES DEL REGIMEN LOCAL.-II. EL PAPEL DE LOS FUNCIONARIOS.-III. LA FUNCION PUBLICA LOCAL EN EL PROYECTO DE LEY.-IV. CONCLUSION.

\section{EL PROYECTO DE LEY REGULADORA DE LAS BASES DEL REGIMEN LOCAL}

En el difícil y no siempre lineal proceso de redistribución territorial del poder que propugnan los artículos 137 y siguientes de la Constitución, le toca ahora el turno a la Administración local, sobre la que el Gobierno acaba de enviar un novedoso Proyecto de Ley a las Cortes. Se regulan en él la organización, las competencias, los medios financieros y el régimen jurídico de Municipios y Provincias, los núcleos territoriales más cercanos al ciudadano, aquellos con los que éste se relaciona e identifica más, sobre todo en el caso de los Ayuntamientos. Proyecto novedoso, entre otras razones de contenido, porque es la primera norma de desarrollo directo del artícul $149,1 .^{\circ}$, de la Constitución, que expresa la concurrencia normativa entre dos órdenes distintos y diferenciados de poder, el Es- 
tado, que asume las «bases del régimen jurídico de las Administraciones públicas» (art. 149, 1., 18), y las Comunidades Autónomas, que tienen competencia para completar o desarrollar el contenido de aquellas bases; contenido necesariamente incompleto para posibilitar en cada Comunidad una normativa que sea expresión de lo que el Tribunal Constitucional ha denominado el derecho a una política propia en el ámbito de los intereses intracomunitarios. Las «bases», pues, se limitan a garantizar una política global y a regular aquellos aspectos que, en cada momento, se entiendan de interés general, pudiendo las Comunidades Autónomas, en ese marco, completar esa regulación de forma diferenciada y en función de los propios intereses comunitarios, siempre, naturalmente, en el contexto de la Constitución y el correspondiente Estatuto de Autonomía, que son también marcos lo suficientemente amplios como para que en ellos quepan las diversas políticas $u$ opciones emanadas de las urnas De ahí, pues, que en este caso los 796 artículos de la todavía vigente Ley de Régimen local de 1955 hayan quedado reducidos a poco más de cien en el Proyecto enviado a las Cortes; ciento quince artículos de los que apenas dieciséis abordan el problema al que me quiero referir, el de la función pública local, el de los funcionarios al servicio de las Corporaciones locales.

\section{EL PAPEL DE LOS FUNCIONARIOS}

El tema de los funcionarios salta de vez en cuando a las páginas de los medios de comunicación con motivo de ciertas noticias aisladas que suelen hacer referencia a aspectos parciales y concretos de la función pública: cuando se producen huelgas, peticiones de aumento de retribuciones, problemas de incompatibilidades o cuestiones de horario y de reloj, asuntos todos ellos que, por muy importantes que sean, se convierten casi en anécdotas cuando no se ponen en relación con los problemas de fondo que hacen referencia a la finalidad última de estos «medios personales de gestión del poder público» a través de los cuales se plasman y concretan los fines del Estado y que constituyen, en la práctica, el auténtico escaparate de la Administración. Y es que, en efecto, cuando nos relacionamos con las Administraciones públicas lo hacemos con funcionarios; cuando la Constitución dice que la Administración sirve con objetividad y eficacia los intereses generales, cuando habla de imparcialidad y transparencia, se está refiriendo también a los fun- 
cionarios. Por eso no somos los funcionarios unos trabajadores normales, y por eso, frente a algunas pretensiones un tanto ingenuas de cambios semánticos que a menudo se utilizan en el lenguaje sindical para designar a los «trabajadores de la Administración pública», no está de más reivindicar el nombre original, que expresa muy bien el contenido de su trabajo, una función pública, un servicio público, remunerado también con dinero público, es decir, de todos, y con el no desdeñable privilegio en los tiempos que corren de no tener que ser sometidos a ninguna medida de reconversión industrial. Ello no excluye, naturalmente, ninguna reivindicación profesional o laboral, pero la idea del servicio público es un punto de partida inexcusable, porque ser funcionario hoy supone en cierto modo, y en algunos casos, un privilegio, requiere por tanto una responsabilidad personal y precisa como corolario de un control social. La reforma de la función pública, desde este punto de vista, es también la reforma de los modos de obrar de la Administración, de la eficacia, del dinamismo, del rendimiento social. En una palabra, de la modernización que supondrá, sin duda, atender a las condiciones de trabajo, pero también a los modos de selección; a la adopción de técnicas que hagan más operativa y eficaz su labor, a la política de promoción y ascenso mejor que a las por lo general inoperantes medidas de carácter disciplinario; en una palabra, a los condicionamientos sociales que determinan los resultados y los rendimientos.

Pretender que una ley, por muy buena que sea, logre taumatúrgicamente todos estos objetivos es hacer un acto de fe excesivamente ciego en la eficacia de las normas jurídicas. Pero la ley puede contribuir a ello, sin ninguna duda. En el caso de los funcionarios locales parece claro que las pocas o muchas competencias que detenten los Municipios estarán en manos de los funcionarios y que las decisiones políticas de los órganos de gobierno no se plasmarán en contenidos tangibles y en mejores servicios para los ciudadanos sin la colaboración decidida de los empleados públicos, sin su preparación técnica y su responsabilidad personal. Pues bien, aun teniendo en cuenta que una ley no puede transformar la realidad de la noche a la mañana, ¿cuáles son las previsiones de la Ley Básica de Régimen local en lo que respecta a la función pública? 


\section{LA FUNCION PUBLICA LOCAL EN EL PROYECTO DE LEY}

A mi juicio, cinco podrían ser los principios o pautas del Proyecto de Ley reguladora de las Bases del Régimen local: simplificación, selección mediante módulos objetivos, homogeneización con los demás funcionarios, intercomunicación entre las distintas Administraciones públicas y equilibrio competencial entre el Estado, las Comunidades Autónomas y las Corporaciones locales en el régimen de los funcionarios de estas últimas.

A) Sin perjuicio de ulteriores precisiones, el personal al servicio de las Entidades locales se integra por tres tipos de empleados: los funcionarios de carrera, los contratados en régimen laboral y el personal eventual de libre designación para puestos de confianza. A los primeros se les reservan, entre otras, las funciones públicas que impliquen ejercicio de autoridad, algunas de las cuales (fe pública, asesoramiento legal, control y fiscalización interna de la gestión económico-financiera, contabilidad, tesorería y recaudación) quedan, a su vez, reservadas a unos funcionarios cuyo sistema de selección comparten el Estado y la Corporación local. Son los denominados, en el Proyecto, funcionarios con habilitación de carácter nacional (secretarios, interventores y depositarios), que se reclutan inicialmente por el Estado, y una vez así «habilitados» estarán legitimados para participar en los concursos de méritos convocados para la provisión de plazas concretas, concursos resueltos por la Corporación local interesada sobre la base de un baremo objetivo de méritos cuya fijación, en un 75 por 100, es general y establece el Estado, y el resto, la Corporación local, en razón a sus características propias, si así lo desea. Conviene, en todo caso, recordar que este sistema de reclutamiento nacional, aunque dando entrada a la participación de las Corporaciones locales en la selección de los llamados Cuerpos nacionales de funcionarios, tiene el apoyo del Tribunal Constitucional, que en su sentencia de 7 de abril de 1983 estableció que la selección y adscripción a plaza concreta de los funcionarios citados puede pertenecer al Estado como núcleo de «las bases» (art. 149, 1., 18) de la regulación estatal de la materia, "pues ello otorga a los funcionarios en cuestión una igualdad de oportunidades y permite una valoración objetiva de los méritos, garantizando asimismo los derechos de los administrados en la misma forma en todo el territorio nacional». 
En este conflictivo aspecto el Proyecto opta, pues, por una vía intermedia entre la completa competencia estatal y el abandono absoluto al localismo en la selección de estos importantísimos funcionarios. Vía intermedia que puede considerarse prudente y operativa y que es, desde luego, perfectamente constitucional. Por eso, no están, a mi entender, justificadas algunas críticas que la prensa ha aireado, provenientes del Consejo General de Colegios de Secretarios, Interventores y Depositarios, en el sentido de que el Proyecto no recoge la "constitucionalidad de los citados Cuerpos", refiriéndose, sin duda, a la citada sentencia del Tribunal Constitucional de abril de 1983. Conviene salir al paso de esta crítica, al menos tal y como está enunciada por la prensa, porque se trata de un planteamiento que ha sido utilizado con anterioridad para oponerse a algún Proyecto de Ley que modificaba o afectaba a leyes anteriores cuya constitucionalidad había declarado antes el Tribunal Constitucional. Late aquí una interpretación sesgada del papel del Tribunal Constitucional, cuya función no es, en este punto, determinar la única opción posible de desarrollo constitucional, sino declarar las que no son compatibles con la Constitución. Para decirlo con palabras del propio Tribunal: "La Constitución es un marco de coincidencias suficientemente amplio para que dentro de él quepan opciones políticas de muy diferente signo. La labor del Tribunal Constitucional no consiste necesariamente en cerrar el paso a las opciones o variantes imponiendo autoritariamente una de ellas». Que una $u$ otra opción guste más o menos dependerá no ya de un juicio de constitucionalidad, sino de un criterio o juicio de valor político, por lo demás perfectamente respetable y, en su caso, atendible por razones de otra índole.

Lo mismo sucede con las «bases» a las que se refiere el artículo 149 de la Constitución. Es el legislador estatal el competente, el que tiene reservada la calificación de lo básico, como ha afirmado también el Tribunal Constitucional; regulación que podrá impugnarse por exceso, pero regulación en todo caso no inamovible en la medida en que representa lo que en ese momento se considera adecuado, según la opción mayoritaria legitimada por las urnas en un régimen de pluralismo político, para garantizar el interés general.

B) La selección mediante módulos objetivos que garanticen la publicidad, el mérito y la capacidad, que es también un principio y una exigencia constitucional (arts. 23, 2. ${ }^{\circ}$, y 103, 3. $)$, se extiende 
igualmente al personal contratado en régimen laboral, de modo que únicamente es libre el nombramiento de los funcionarios de empleo eventuales para puestos de confianza, cuyo número y retribución fijará el Pleno de la Corporación al iniciar su mandato y cuyas funciones no podrán ser nunca las que correspondan a los funcionarios de carrera. Estos funcionarios cesan al acabar el mandato de la autoridad $\mathrm{u}$ órgano que los nombró.

C) En tercer lugar, el Proyecto trata de homogeneizar el régimen de los funcionarios locales y el de los demás funcionarios públicos en numerosos aspectos. Así, la jornada laboral será igual a la de los funcionarios estatales e idénticos los sistemas de participación sindical y protección social. Se dispone también que las retribuciones básicas tengan la misma estructura y cuantía para todos los funcionarios y que las complementarias se adecúen a los mismos criterios objetivos, siendo la Corporación local quien fije su cuantía concreta dentro de los límites que señale el Estado.

D) Esta homogeneización es importante y necesaria para atender a lo que quizá sea la mayor novedad del Proyecto: la intercomunicabilidad de los funcionarios de todas las Administraciones públicas. Los puestos de trabajo - dice uno de los preceptos de este Proyecto de Ley - se proveerán normalmente por concurso de méritos entre funcionarios que pertenezcan a cualquiera de las Administraciones públicas. Intercomunicabilidad que va a exigir, sin duda, algún tipo de unificación de Cuerpos y el establecimiento de técnicas de equiparación o, lo que es lo mismo, la fijación de programas similares de selección para funcionarios de idéntica o parecida función en todas las Administraciones públicas; esfuerzo nada fácil de conseguir, por cierto, si se tiene en cuenta la tradicional dispersión y diferenciación de Cuerpos que caracteriza a la función pública española, aunque muchos de ellos cumplan tareas similares. Ello supone también un cierto grado de coordinación y la remisión del problema a la más amplia reforma general de la función pública que se tiene anunciada.

E) Por último, el Proyecto trata de establecer un cierto equilibrio competencial entre el Estado, las Comunidades Autónomas y las Corporaciones locales en materia de funcionarios de estas últimas. La regulación de este tipo de funcionarios va a estar constituida por las normas insertas en este Proyecto de Ley, la legislación general básica de todos los funcionarios (art. 149, 1.․,18) de la Constitución) y la legislación de las Comunidades Autónomas que 
complemente a ambas. Sin perjuicio, pues, de lo que estas leyes dispongan en su día, de momento, el Proyecto de Ley Básica de Administración local atribuye al Estado unas cuantas competencias que tratan de salvaguardar el principio de homogeneidad antes enunciado. Por ejemplo, corresponde al Estado fijar los límites que las Corporaciones locales no pueden rebasar en materia de gastos de personal, establecer las normas con arreglo a las cuales han de confeccionarse las relaciones de puestos de trabajo, las condiciones de su creación y las normas básicas de la carrera administrativa, señalar los límites máximos y mínimos dentro de los cuales las Corporaciones locales fijarán la cuantía de las retribuciones complementarias, adoptar las reglas básicas y programas mínimos para seleccionar a los funcionarios que no requieran habilitación nacional, así como establecer los títulos académicos mínimos requeridos para tomar parte en dichas pruebas... Las Corporaciones locales, de otro lado, aprueban la plantilla de su personal y la relación de puestos de trabajo, fijan las retribuciones complementarias, seleccionan directamente a todos sus empleados, excepto a los funcionarios que requieren habilitación nacional, aunque también aquí tienen una cierta participación... En medio, a las Comunidades Autónomas les corresponderá el desarrollo normativo de este Proyecto de Ley, así como el de la legislación general básica de todos los funcionarios, donde se podrán concretar aspectos que ahora quedan pendientes de determinación.

\section{CONCLUSION}

¿Qué pensar de esta reforma? No son ciertamente muchas las cosas que dice o innova el Proyecto de Ley. La más importante de ellas es, sin duda, la equiparación de los funcionarios locales a los del Estado y la posibilidad de trasvases entre las distintas Administraciones, que hasta ahora no existía. La propia dinámica del Estado autonómico no permitía, seguramente, en la regulación básica de los funcionarios locales, ir mucho más allá de la fijación de principios, pautas y reglas que garanticen un tratamiento igualitario de los derechos de todos los ciudadanos. El diseño completo de la función pública local habrá de esperar a las normas de desarrollo, en las que cabrán matices y diferencias, aunque también funcionará en la mayoría de ellas el síndrome de imitación respecto de las primeras que se dicten, por otra parte, muy natural, como ya ha suce- 
dido con otras normas anteriores de muchas Comunidades Autónomas.

El Proyecto, ciertamente, otorga importantes posibilidades de promoción e igualación a los funcionarios locales. Desde ese punto de vista es una regulación que afecta e interesa, sobre todo, a los propios funcionarios. Para el resto de los ciudadanos, para aquellos en función de quienes debe hacerse la tantas veces repetida reforma de la Administración, la ley que se pretende aprobar dice poco en este punto, aunque seguramente no podía decir más. El justificado derecho a una Administración más eficaz, más cercana, más participativa y transparente, prestando unos servicios públicos de mejor calidad, debe buscarse en otro sitio. En la gestión política, en los medios financieros, en las competencias administrativas. A estos problemas el Proyecto trata de aportar también una respuesta que el tiempo se encargará de juzgar si es o no operativa. Por lo que respecta a la función pública, que es el instrumento necesario para concretar y hacer tangibles los fines y objetivos a los que debe servir la Administración, habrá que dar a los funcionarios instrumentos, medios, condiciones de trabajo, estímulos, vías de promoción... Sólo después se podrá exigir razonablemente el control; control administrativo, pero también social. Este Proyecto es un intento de aportar algo de lo primero. El resto corresponde, en función de sus propias competencias, a las Corporaciones locales, a las Comunidades Autónomas, a los propios funcionarios. $\mathrm{Y}$ también al Estado, por supuesto. Será preciso conocer la realidad y las necesidades, en función del trabajo de cada Municipio, para ordenar adecuadamente los medios disponibles. En este sentido, por tratarse de un trabajo innovador y por la experiencia que incorpora, no quisiera dejar de referirme a un reciente libro publicado por el Gobierno vasco que trata de evaluar esas necesidades. Organización funcional y valoración de puestos en la Administración local vasca se llama, y es un ejemplo a tener muy en cuenta, porque para legislar adecuadamente es preciso antes conocer la realidad. Las leyes y las normas, con todo, no son ninguna panacea. Porque si la burocracia evoca, a veces, un mundo de papeles, de lentitud y de ineficacia, sin embargo, como ha dicho un autor francés, "cuando șe estudia el tema sin prejuicios y con un deseo de análisis eficaz aparecen las nociones, como siempre, menos simples, los reproches más difíciles de localizar, el terreno más rebelde a la delimitación y los remedios más difíciles de encontrar». 